Araştırma Makalesi / Research Paper

\title{
İlim Değişikliğine Karşı Mekânsal Kırılganlığın ve Uyum Kapasitesinin Belirlenmesi: Alanya Örneği
}

\author{
Duygu GÖKÇE ${ }^{1^{*}}$, Z. Betül PANCAR ${ }^{1}$, Ali TÜRK ${ }^{1}$ \\ ${ }^{1}$ Süleyman Demirel Üniversitesi, Mimarlık Fakültesi, Isparta \\ Geliş Tarihi (Received): 08.03.2018, Kabul Tarihi (Accepted): 02.04.2018 \\ $\square$ Sorumlu Yazar (Corresponding author ${ }^{\star}$ ): duygugokce@sdu.edu.tr \\ (C) +902462111607 且 +902462118231
}

\section{ÖZ}

İklim değişikliğinin kıyı yerleşimlerinin ekosistemi, nüfusu, ekonomisi, yapılı çevresi ve altyapısı üzerinde olumsuz etkileri bulunmaktadır. Yerleşimlerin altyapı hizmetlerine erişilebilirliği ve kalitesindeki yetersizlikler, etkin olmayan arazi kullanım plan ve politikaları, yetersiz yatırımlar, afet direnci zayıf yapı stoğu vb. bu etkilerin artmasına, dolayısıyla yerleşimlerin iklim değişikliğine karşı direncinin ve uyum kapasitesinin zayıflamasına neden olmaktadır. İklim değişikliği ile baş edebilmek için uyum stratejileri ve esneklik düşüncesine dayalı planlama yaklaşımı son yıllarda kent yazınında gündeme gelmektedir. Bu kapsamda kentsel arazi kullanım politika ve planları; yerleşimlerin morfolojik yapılarını, başka bir deyişle, mekânsal gelişme biçim, yön, büyüklük ve niteliğini, sektörel kararları, kullanımların yer seçimini, yapılaşma koşullarını belirler ve yerleşimlerin uyum kapasiteleriyle yakından ilişkilidir. Makalede, iklim değişikliği risklerinden deniz seviyesinin yükselmesi ve sıcaklık artışı riskleriyle karşı karşıya olan Alanya kıyı yerleşiminin kırılganlığı incelenmiş; mevcut Çevre Düzeni Planının bu kırılganlığı dikkate alıp almadığı veya uyum sağlamayı destekleyip desteklemediği analiz edilmiş ve Alanya'nın uyum kapasitesini güçlendirebilecek mekânsal stratejiler geliştirilmiştir.

Anahtar Kelimeler: Kırılganlık, uyum kapasitesi, iklim değişikliği, kentsel arazi kullanım planı, mekânsal stratejiler

\section{Determining the Spatial Vulnerability and Adaptation Capacity to Climate Change: A Case Study of Alanya}

\begin{abstract}
Climate change has negative effects on the ecosystem, population, economy, built environment, infrastructure of coastal settlements. Inadequate accessibility and quality of the infrastructure and services of the settlements, inefficient land use plans and policies, insufficient investments, disaster resistance weak building stock etc. lead to an increase in the impacts, hence the weakening of the resistance and adaptation capacity of the settlements to climate change. In order to cope with climate change, adaptation strategies and flexibility-based planning approach have been on the agenda in urban literature in recent years. In this context, urban land use policies and plans determine the morphological structures of the settlements, in other words, the spatial development style, direction, size and quality, sectorial decisions, location of uses, conditions of settlement and are closely related with the adaptation capacities of the settlements. In the article, the vulnerability of the Alanya coastal settlement, which faces the risks of sea level rise and temperature increase of climate change, was examined; it was analyzed whether the current Environmental Plan is taking into account this vulnerability or whether it is supporting adaptation; and spatial strategies that can strengthen the adaptation capacity of Alanya have been developed.
\end{abstract}

Keywords: Vulnerability, adaptability capacity, climate change, urban land use plan, spatial strategies 


\section{Giriş}

Günümüzün en önemli ekolojik sorunu olan iklim değişikliğinin deniz seviyesinde yükselmeler, sel ve kuraklıkların artması, daha güçlü fırtına olayları, aşırı sıcaklık artışları, daha sık ve yoğun orman yangınları, tarımsal verimsizlik, biyoçeşitliliğin azalması gibi sonuçlara yol açması beklenmektedir. Bununla birlikte, iklim değişikliği ile ilgili araştırmalar ne kadar önlem alınırsa alınsın önümüzdeki yıllarda iklim değişikliğinin kaçınılmaz olacağı konusunda hemfikirdir. Temelde insan kaynaklı aktiviteler (kontrolsüz nüfus artışı, arazi kullanım değişiklikleri, fosil yakıt kullanımı, ekonomik kalkınma aktiviteleri vb.) iklim değişikliğine neden olmakta ve bunda kentsel arazi kullanım politikaları önemli rol oynamaktadır. Ormanları, tarım arazilerini, su kaynaklarını vb. tehdit eden / yok eden, konut-işyeri arasındaki mesafeyi artıran kentsel yayılma; kentsel Isı adası etkisini artıran, açık-yeşil alan miktarının az olduğu yüksek yoğunluklu yapılaşma; dere yatakları gibi riskli alanlarda yerleşme; iklim koşullarına duyarsız biçimde tasarlanıp inşa edilmiş yapı stoğu vb.; kısaca ekolojik faktörlerden çok, büyük oranda sermaye taleplerinin yönlendiriciliğinde gerçekleşmiş kentleşmeyle, yerleşmelerin iklim değişikliği tehditlerine karşı sürdürülebilirliği ve direnci / dayanıkııı̆ı zayıflamaktadır. Bu bağlamda yerleşmelerin söz konusu baskılar ve potansiyel iklim değişikliği tehditleri altında sürdürülebilirliğinin nasıl sağlanabileceği veya direncinin nası arttırılabileceği ve bunun nasıl bir planlama yaklaşımıyla ele alınabileceği soruları önem kazanmaktadır.

Kentler giderek artan sıklıkta ortaya çıkan küresel nitelikli ekonomik, ekolojik ve politik etkilere uyum sağlamak, belirsiz ve beklenmedik değişikliklere tepki vermek ve bu sırada işlevlerini - işlerliklerini sürdürmek zorundadır. Bu değişimlere hazırlıklı olma, bunları yönetme ve bunlarla başa çıkmak için yeni ve beklenmedik durumlara uyum sağlamada son yıllarda kent yazınında esneyebilirlik (resilience) düşüncesi hakim olmaya başlamıştır. Kentsel planlama geleneksel olarak tehdit, risk ve bunların olumsuz etkilerini olabildiğince azaltacak önlemler almaya odaklanmıştır. Esneyebilirlik yaklaşımı ise planlamanın görev alanını genişleterek bu tehdit ve olumsuz etkiler karşısında alınacak önlemleri ve yapılacak eylemleri de gündeme getirmiştir. Başka bir ifadeyle, bu yaklaşımın ana düşüncesi, kent sisteminin söz konusu değişimleri özümseyebilmesi, kendini yeniden düzenleyebilmesi ve herhangi bir afet sonrasında ortaya çıkan koşulları yöneterek uyum sağlamasıdır (Eraydın ve ark., 2011).

Esneyebilirlik yaklaşımı, iklim değişikliği bağlamında ele alındığında, iklim değişikliğinin yaratacağı sorunların üstesinden gelebilecek, uyarlanabilmeyi destekleyecek stratejiler geliştirebilen bir planlamayı gerekli kılar. Yer- leşimlerin iklim değişikliği tehditleri altında sürdürülebilirliğinin nası sağlanabileceği veya direncinin nasıl arttırılabileceği konuları ise, iklim değişikliği ile mücadelede temel politikalardan biri olan adaptasyon politikalarıyla yakından ilişkilidir. Adaptasyon politika ve planları, iklim değişikliğinin insanlar ve yerleşimi destekleyen ekosistemler üzerindeki tahmini etkilerini en aza indirmek için alınacak önlemleri ve eylemleri tarif eder ve adaptasyon önlemlerinin etkileri coğrafya ile sınırıdır.

Esneyebilirlik temelli planlama yaklaşımının ve benzer şekilde iklim değişikliğine adaptasyon politikalarının ana bileşenleri; kırılganlık ve uyum kapasitesidir. İklim değişikliği tehditleri yerleşimler, diğer bir deyişle, kentsel (ve kentsel alanları oluşturan sistemler) ve kırsal alanlar üzerinde belirli etkilere sahiptir ve bu etkiler yerleşimin kırılganlığı ile ilişkilidir. Kırılganlık insanların, ekosistemlerin ve yapılı çevrenin maruz kaldığı iklim değişikliği tehditlerinden zarar görme eğilimi; uyum kapasitesi ise, iklim değişikliğine uyum sağlama ve bunu şekillendirme kapasitesi olarak tanımlanabilir.

Özellikle kıyı kentleri ya da yerleşimleri, deniz seviyesinin yükselmesi riski altında olduğu için, iklim değişikliğinden etkilenen en hassas coğrafi bölgelerde yer almaktadır. Bu yerleşimler, taşkınlar ve erozyonların oluşumu, tuzlu su girişi, altyapı ve ekilebilir arazi kayıpları, içilebilir suyun azalması ve kirlilik, kıyı ekosistemlerinin tahribatı veya kaybı, turizm sektöründe ekonomik zararlar vb. olası etkilerle başa çıkmada üretilen mekânsal kararlar gereği genellikle savunmasız ya da düşük dirençli yerleşimlerdir.

Makalede, iklim değişikliği tehditlerinden deniz seviyesi yükselmesi ve sıcaklık artışı riskleri taşıyan ve bu bakımdan kırılgan bir yapıda olan Alanya kıyı yerleşimi ele alınmış; esneyebilirlik düşüncesine dayalı planlama yaklaşımı çerçevesinde, mevcut Çevre Düzeni Planının ne ölçüde Alanya'nın kırılganlığını dikkate aldığını ya da iklim değişikliği tehdit ve etkilerine uyum sağlamayı desteklediğini araştırmak ve iklim değişikliği etkilerine mekânsal açıdan nasıl dirençli hale getirebileceği ya da mekânsal uyum kapasitesinin nasıl güçlendirilebileceği sorusuna yanıt aramak amaçlanmıştır.

Makalenin amacıyla ilintili olarak ve esneyebilirlik düşüncesi taşıyan bir planlama yaklaşımına dayanarak yöntemi üç aşamadan oluşmaktadır:

1. Aşama: Alanya'nın potansiyel iklim değişikliği tehditleri, ilgili uzmanların analiz ettiği deniz seviyesi ölçüm bilgileri ile mevcut iklim verileri ve senaryolarına dayanılarak belirlenmiş; bu tehditlere hangi alanların ve sektörlerin daha fazla maruz kalabileceği tanımlanmış; bunun olası etkileri konusunda öngörüler geliştirilmiş; mekânsal açıdan kııılgan bölgeler belirlenmiş- 
tir. Mekânsal açıdan kırılgan bölgelerin belirlenebilmesi için ilk olarak, Alanya beldelerine ilişkin rakım bilgileri elde edilmiş (URL-1, 2017), bunlar mekânsal verilerle çakıştırılarak alçak rakımlı kıyı bölgeleri elde edilmiştir. Bu bölge içerisindeki kullanımlar, arazi kullanım haritaları incelenerek saptanmıştır. İkinci aşamada, Alanya kentleşmiş alanında yüksek yoğunluklu bölgeler, arazi kullanım haritaları üzerinden yoğunluklar hesaplanarak ve geçirimli alanlar (park alanları) belirlenerek elde edilmiştir. Öte yandan, iklim değişikliğini tetikleyen diğer dış baskılar tanımlanarak nasıl kırılganlıkların artışına neden oldukları ortaya konulmuştur.

2. Aşama: Çevre Düzeni Planının ne ölçüde Alanya'nın kırılganlığını dikkate aldığı, bu bağlamda Alanya'nın iklim değişikliği tehdit ve etkilerine karşı uyum kapasitesinin ne olduğu değerlendirilmiştir. Bunun için Antalya-Burdur-Isparta Planlama Bölgesi Çevre Düzeni Planı, Çevre ve Şehircilik Bakanlığı resmi internet sitesinden raster formatında indirilerek birleştirilmiştir. Çevre Düzeni Planında 0-10 m alçak rakımlı kıyı bölgesi için öngörülen mekânsal gelişme kararları belirlenerek hesaplanmış ve uyum kapasitesi bağlamında değerlendirilmiştir.

3. Aşama: Kırılganlık ve uyum kapasitesi değerlendirmeleri sonucunda, Alanya'nın potansiyel iklim değişikliği etkilerine dirençli hale getirilebilmesi ya da uyum kapasitesinin güçlendirilebilmesi için stratejiler geliştirilmiştir.

\section{ALANYA'NIN IKLIM DEĞişiKLIĞínE KARŞI KIRIL- GANLIĞI}

Antalya'nın önemli turizm merkezlerinden biri olan Alanya, iklim değişikliğinin etkilerine açık ve kırılgan bir kıyı yerleşimidir. Doğu Akdeniz'e kıyısı olan Alanya, iklim değişikliği risklerinden deniz seviyesi yükselmesi sorunuyla karşı karşıyadır. Öztürk (2011)'ün, 19722009 yılları arasında doğu Akdeniz'deki deniz seviyesi ölçümlerini analiz ettiği çalışmasına göre, "Akdeniz 20. yüzyılda deniz seviyesi yükseliminin en fazla olduğu alanlardan biridir ve bu artışın en fazla gerçekleştiği kesim doğu Akdeniz'dir. Analiz sonuçlarına göre, tüm deniz seviyesi dizilerinde ve sıcaklık dizisinde istatistiksel açıdan anlamlı artış eğilimleri vardır. Bu eğilimlerin oranları, ortalama deniz seviyesinde $+1.57 \mathrm{~mm} / \mathrm{yıl}$, ortalama maksimumda $+1.89 \mathrm{~mm} / \mathrm{yll}$, ortalama minimumda $+1.36 \mathrm{~mm} / \mathrm{yll}$, sıcaklıkta ise $0.026^{\circ} \mathrm{C} / \mathrm{yıl}$ 'dır. Uzun süreli ortalamalara göre yıl içerisinde $14.9 \mathrm{~cm}$ 'lik bir genlik görülürken, genliğin en yüksek seviyesine Ağustos ayında ulaşılır. Yıllar arası ortalama maksimum ve minimum deniz seviyesi değerlerinde, $36.5 \mathrm{~cm}$ düzeyinde bir genlik söz konusudur."
Alanya, deniz seviyesi yükselmesi riski yanı sıra, iklim değişikliğine bağlı sıcaklık artış riski de taşımaktadır. Daha açık bir anlatımla, ülkemizin yer aldığı Akdeniz Havzası iklim değişikliği kaynaklı tehditler / riskler açısından kritik konumdadır. Havza için tanımlanan riskler, daha sıcak yaz ayları, karasal bölgelerdeki ve denizlerdeki biyoçeşitlilik kayıpları, su kıtlıkları, bulaşıcı hastalıkların artması vb. dir. İklim senaryoları (2031-2060 yılları için) $2^{\circ} \mathrm{C}$ 'lik küresel sıcaklık artışın Akdeniz Bölgesi'nde $1-3^{\circ} \mathrm{C}$ arasında değişen sıcaklık artışlarına neden olacağını göstermektedir. Buna göre, yaz aylarında sıcaklık değerlerinde ciddi yükselmeler görülürken, en sıcak gün sayısı ve sıcak hava dalgalarının sıklığında da artışlar olacaktır. Ayrıca havzada yağış oranının düşeceği, ciddi kuraklıkların yaşanabileceği ileri sürülmektedir. Antalya bölgesinde de yıllık ortalama yağış miktarlarındaki düşüş ile sıcaklık artışlarının ciddi etkileri görülmeye başlamıştır (Eliasson ve ark., 2010).

Antalya'da yaz mevsimi ortalama sıcaklıkları oldukça yüksektir. 1971-2000 yılları arasındaki verilere göre Ağustos ayı ortalamaları $26-27^{\circ} \mathrm{C}$ derece olup, kıyı kesiminde $28-29^{\circ} \mathrm{C}$ derecelere ulaştığı görülmektedir. Ancak, bu ortalamalarda artışlar olduğu ve ortalama değerlerin 2009 yılında $1^{\circ} \mathrm{C}$ arttığı görülmektedir (Şensoy ve Demircan, 2007). Ayrıca Antalya'nın önemli bir bölümünde yağışların azaldığı, geleceğe yönelik iklim değişikliği senaryolarında ise durumun daha çarpıcı olduğu görülmektedir. Türkeş (2001) emisyon artışlarının denetlenmediği bir senaryoya göre, 2080 yılına kadar 1961-1990 ortalamalarına göre 3-4 C० derece artı̧̧ olacağını; emisyonların belirli bir ölçüde denetlendiği diğer bir senaryoda yaz ve kış sıcaklık ortalamalarında $3-3,5^{\circ} \mathrm{C}$, ilkbahar ve sonbaharda $2-3 \mathrm{C}^{\circ}$ sıcaklık artış olacağını öngörmektedir. Bu bulgulara göre Alanya da sıcaklık artışı potansiyel tehdidiyle karşı karşıyadir.

Bu veriler; Alanya'ya ilişkin iklim değişikliği tehditlerinin temelde deniz seviyesinin yükselmesi ve sıcaklık artışı olduğunu ortaya koymaktadır. Bu noktada Alanya'nın iklim değişikliği açısından kırılgan bir yapısının olup olmadığı ya da ne düzeyde bir kırılgan yapıya sahip olduğu sorusu önem kazanmaktadır.

İlgili literatürde, kırılganlık düzeyinin belirlenmesinde yerleşimlerin fiziksel, morfolojik, sosyo-ekonomik ve politik-kurumsal özellikleri dikkate alınmaktadır (Watts ve Bohle, 1993; Cutter ve ark., 2003; Balica ve ark., 2012). Örneğin, rakım, deniz seviyesi yükselmesi, alçak rakımlı kıyı bölgesi, orman alanları vb. fiziksel göstergeler olarak ele alınabilmektedir. Deniz seviyesi yükselmesi tehdidi bağlamında, daha yüksek rakım ve daha fazla orman alanı daha düşük kırılganlıkla ilişkilendirilebilir. 0-10 metrelik alçak rakımlı kıyı bölgelerindeki kent- 
leşmiş alanın fazla olması yüksek kırılganlığa neden olabilir. Parklar (kent boşlukları), sahil boyunca inşa edilen alan uzunluğu, yapılı alanın (kültürel miras yapıları, hastaneler, huzurevleri gibi hizmet yapıları da dâhil) denizden ortalama uzaklığı, altyapı hizmetlerine erişim, kentleşmiş alandaki yapı yoğunluğu vb. morfolojik göstergeler olarak değerlendirilebilmektedir. Yapılı alanın denize olan mesafesinin fazla olması, kent boşluklarının ya da parkların fazla olması düşük kırılganlıkla ifade edilebilir. İnşa edilen sahilin uzun olması ve altyapının yaygınlığı, yüksek yapı yoğunluğuna sahip alanın varlığı, yüksek kırılganlıkla karakterize edilebilir.

Nüfus, yaş, cinsiyet, ırk, etnik köken, eğitim, aile yapısı, sosyal bağımlıık, gelir, meslek, iş kaybı, politik güç, kiracılık, ticaret ve endüstrinin kalite ve yoğunluğu vb. sosyo-ekonomik göstergeler olarak kullanılabilmektedir. Hızlı nüfus artışı, eğitim seviyesinin düşüklüğü, düşük gelir, enformel işlerde çalışma, işsizlik, kirada oturma vb. kırılganlığı artırmaktadır. Kadın nüfusu, engelli nüfus, faklı ırk ve etnik kökenden olan nüfus, sosyal hizmetlere bağımlı nüfus, 65 yaş ve üstü yaşlı nüfus, kırsal nüfus, geniş aileler; olası bir afet sonrası eskiye dönme süreci, kaynaklara ve hizmetlere erişim, özel gereksinim ve bağımlılıktan kaynaklı kısıtlı haraketlilik açısından iklim değişikliğine karşı daha hassas / duyarlı nüfus olarak nitelendirilmektedir. Ticaret ve endüstrinin kaliteli ve yoğun olması, toplumun iyi oluşunu gösterir ve potansiyel kayıpları ve eskiye dönüş için harcanacak süreyi azaltabilir. Tıbbi hizmetler, kurumsal düzenlemeler, taşkın tehlike haritaları vb. politik-kurumsal göstergeler arasında sayılabilir. Doktor, hemşire ve hastane sayısı- nın fazla olması, taşkın tehlike haritalarının varlığı daha düşük kırılganlığı gösterebilir.

Morfolojik göstergeler dışındaki göstergeler makalenin kapsamı dışındadır. Alanya'nın bahsi geçen iklim değişikliği tehditlerine karşı kırılganlık düzeyinin tespitinde, kentsel arazi kullanım kararlarıyla şekillenen morfolojik yapısı önemli rol oynamaktadır. Bu kapsamda hangi alanların ve dolaylı olarak hangi sektörlerin bu tehditlere maruz kalabileceğini saptamak ve tehditlerin olası etkilerini öngörmek kırılganlığın boyutunu görünür kılacaktır.

Deniz seviyesinin yükselmesi bağlamında en risk altındaki alanlar, deniz seviyesinden 0-10 metre arasında yüksekliğe sahip alçak rakımlı kıyı bölgeleri olduğu için, Alanya'nın alçak rakımlı kıyı bölgesi (1,778 ha) belirlenmiştir (Şekil 1). Bu bölge içerisinde yer alan yapılı çevre, ekosistem, bu bölgede yaşayanlar ve turizm sektörü deniz seviyesi yükselmesi riskine maruz kalabilecektir. Bölge tamamen yapılaşmıştır ve içerisinde konut varlıkları, kamu binaları, kültürel miras yapıları, altyapı tesisleri (kurvaziyer limanı), turizm tesisleri, sanayi alanı vb. yer almaktadır. Bu varlıklar olası bir taşkından zarar görebilir ve afet sonrası geri dönüşümleri de oldukça maliyetli olabilir. Alanya'da turizm kıyıda yoğunlaştığı için deniz seviyesinin yükselmesi sonucu oluşan kıyı erozyonları, taşkınlar ve altyapıdaki bozulmalar yaz mevsimindeki turizm talebini azaltabilir, turizm sezonunun kısalmasına neden olabilir, turistlerin güvenliğini ve konforunu etkileyebilir.

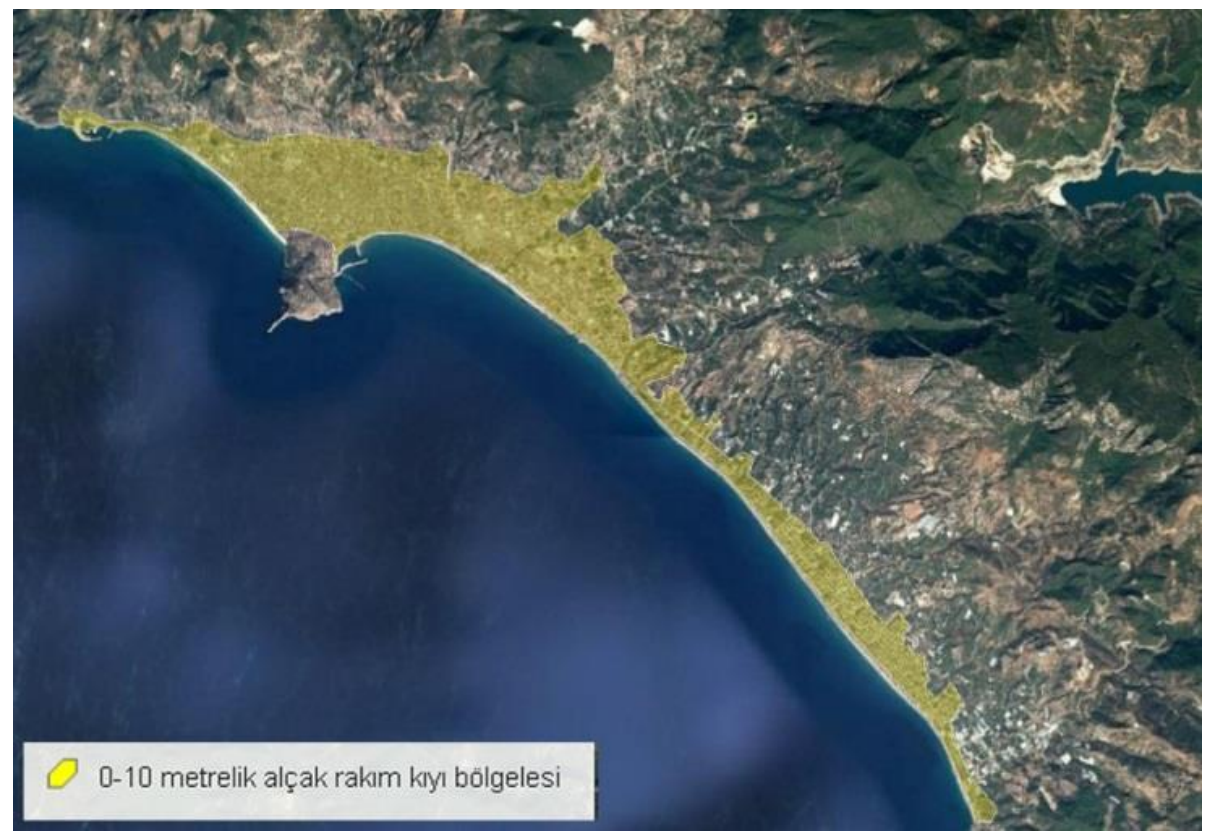

Şekil 1. Alanya'nın 0-10 metrelik alçak rakım kıyı bölgesi 
Diğer bir iklim değişikliği riski olan aşırı sıcaklık artışlarına, tüm yapılı çevre, yaşayanlar, ekosistem, tarım ve turizm sektörleri maruz kalabilecektir. Sıcaklıklardaki artış özellikle yoğun yapılaşmış ve geçirimsiz arazi yüzeyinin fazla olduğu kentleşmiş alanlarda daha etkili olacaktır. Nitekim kentsel ısı adalarının $12^{\circ} \mathrm{C}$ 'ye kadar ek sıcaklığa yol açtığı araştırmacılar tarafından öne sürülmektedir (ör. Hawkins ve ark., 2004). Şekil 2 ve 3'de yüksek yoğunluklu ve parkların oldukça az olduğu, dolaysıyla kentsel ısı adası etkisinin fazla olduğu riskli alanlar gösterilmiştir.

Isı adası etkisi hem yaşayanların sağlığını olumsuz etkileyebilmekte hem de çok fazla enerji tüketen iklim- lendirme aygıtlarının kullanımını artırarak iklim değişikliğini tetikleyebilmektedir. Yaz sıcaklıklarında ortaya çıkan belirgin değişim (daha sık ve daha yoğun sıcak hava dalgaları, düşük yaz yağışları) ekosistemi, Alanya'nın tarım ve turizm sektörlerini olumsuz etkileyebilecektir. Bitkilerin ve su kaynaklarının $\mathrm{CO}_{2}$ tutma kapasitesinin azalması, su arzının kalite ve miktarının düşmesi, toprağın kalitesinin ve tarımsal verimliliğin düşmesi, biyoçesitliliğin bozulması hatta yok olması potansiyel etkilerden bazılarıdır. Ayrıca yaz aylarındaki sıcak artışı turistler için Alanya'nın çekiciliğini azaltabilir, sıcaklığa bağlı bulaşıcı hastalıkların artmasına neden olabilir, ek enerji talebine ve yüksek işletme masraflarına yol açabilir.

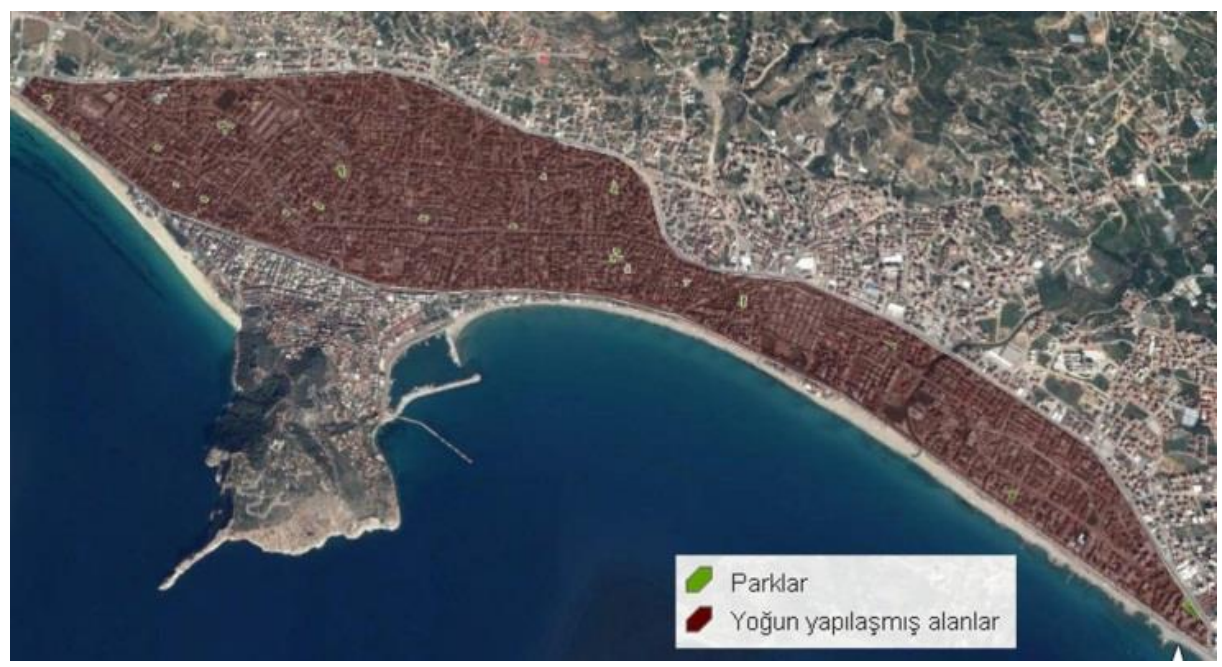

Şekil 2. Yüksek yoğunluklu yapılaşmış alanlar

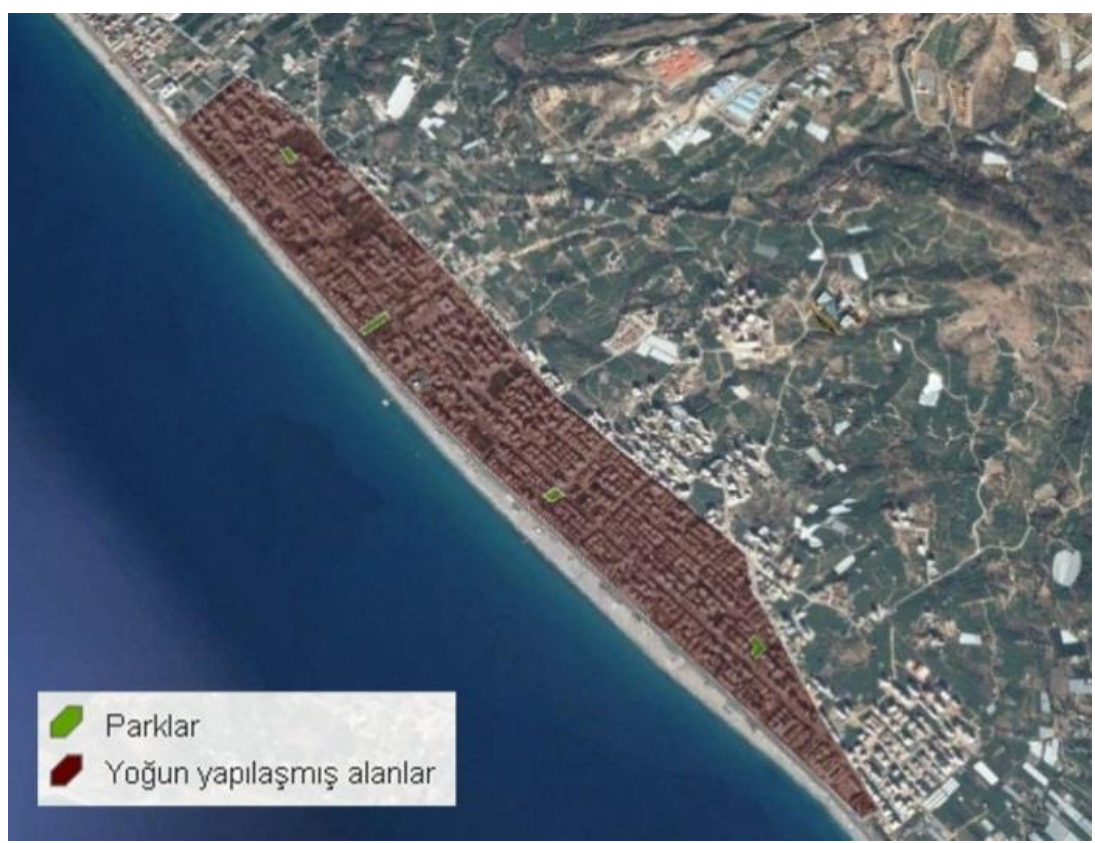

Şekil 3. Yüksek yoğunluklu yapılaşmış alanlar 
Tüm bu veriler, Alanya'nın iklim değişikliği bağlamında mekânsal açıdan kırılgan bir yapısının olduğunu ortaya koymaktadır. İklim değişikliği tehditleri yanı sıra, Alanya'nın sürdürülebilir gelişimini olumsuz etkileyen ve iklim değişikliğini tetikleyen dış baskılar (hızlı nüfus artışı ve göç, turizm yatırımlarına bağlı doğal kaynaklar üzerinde artan baskı ve kentsel yayılma) da bulunmaktadır. 1980 sonrası Turizm Teşvik Yasası ile turizm yatırımlarının artması, buna dayalı hizmet sektörünün gelişmesi, yeni istihdam olanaklarının oluşması ve ikinci konut gelişimi, Alanya'da hızlı nüfus artışına (TUİK verilerine göre, 2010-2016 döneminde nüfus artış oranı binde 17 'dir) ve göç alımına neden olmuştur. Hızlı nüfus artışına bağlı olarak artan kentsel alan talebi özellikle kent merkezinde / kıyı bölgelerde yüksek katlı ve sık yoğunluklu yapılaşmaya ve yeşil alanların azalmasına (dolayısıyla kentin karbon bütçesi ve su kaynaklarının olumsuz etkilenmesine) neden olmuştur. Yoğun yapılaşmanın, bu bölgelerde kentsel ISı adası etkisini ve buna bağlı enerji tüketimini arttırdığı muhtemeldir. Buna ek olarak, yaz aylarındaki aşırı nüfus artışı ve kıyıda yoğunlaşan turizm yatırımları nedeniyle altyapı ve doğal kaynaklar (su kaynakları, tarım arazileri, ormanlar gibi) üzerindeki baskı artmaktadır. Nüfus yoğunluğunun yaz aylarında turizmle birlikte önemli ölçüde artması elektrik ve su tüketimini artırmaktadır. Turizm sektörü ürettiği $\mathrm{CO}_{2}$ emisyonları nedeniyle aynı zamanda iklim değişikliğinin kaynaklarından biridir. Diğer bir dış baskı olan kentsel yayılma, karasal ve tatlı su ekosistemini olumsuz etkilemektedir. II Çevre Durum raporlarına göre (URL-2, 2007; URL-3, 2015); 2007 yılı ile 2015 yılı arasında Alanya'da tarım arazileri \%32 oranında, ormanlar \%19 oranında azalmıştır. Bu dış baskılar sonucu, yutak alanı olarak nitelendirilen su kaynakları, ormanlar ve tarım arazilerinin yitirilmesi ile bunların karbon tutma kapasiteleri de yitirilmiş olmakta, böylece Alanya'nın iklim değişikliğine karşı kırılganlığı daha da artmaktadır.

\section{ÇEVRE DÜZENI PLANININ UYUM KAPASITESI BA- KIMINDAN DEĞERLENDİRILMESi}

14.06.2014 tarih ve 29030 sayılı Resmi Gazete 'de yayımlan Mekânsal Planlar Yapım Yönetmeliği'nde Çevre Düzeni Planı, "Varsa mekânsal strateji planlarının hedef ve strateji kararlarına uygun olarak orman, akarsu, göl ve tarım arazileri gibi temel coğrafi verilerin gösterildiği, kentsel ve kırsal yerleşim, gelişme alanları, sanayi, tarım, turizm, ulaşım, enerji gibi sektörlere ilişkin genel arazi kullanım kararlarını belirleyen, yerleşme ve sektörler arasında ilişkiler ile koruma-kullanma dengesini sağlayan $1 / 50.000$ veya $1 / 100.000$ ölçekteki haritalar üzerinde ölçeğine uygun gösterim kullanılarak bölge, havza veya il düzeyinde hazırlanabilen, plan notları ve raporuyla bir bütün olarak hazırlanan plandır" şeklinde tanımlanmıştır. Buna göre, Çevre Düzeni Planları sektörel ve mekânsal gelişim kararlarının üretildiği ve alt ölçekli planları yönlendiren önemli bir plan kademesidir.

644 sayılı Kanun Hükmünde Kararnamenin 7. maddesi uyarınca 15.04.2014 tarihinde onaylan Antalya-BurdurIsparta Planlama Bölgesi 1/100.000 ölçekli Çevre Düzeni Planının Alanya yerleşimine ilişkin kısmı, makale kapsamında incelenmiştir.

İklim değişikliğine adaptasyon politikaları ve esneyebilirlik düşüncesine dayalı planlama yaklaşımı çerçevesinde, Çevre Düzeni Planının ne ölçüde Alanya'nın kırılganlığını dikkate aldığını ya da iklim değişikliği tehdit ve etkilerine uyum sağlamayı desteklediğini saptamak için; makro form, riskli alanlardaki yer seçim ve yapılaşma niteliği, altyapı yatırımları, ormanların ve tarım alanlarının korunma durumu, olası tehlikelere karşı alternatifler barındırma durumu vb. açılardan sektörel ve mekânsal planlama kararları irdelenmiştir. Düşük rakımlı kıyı bölgesi en hassas ya da en kırılgan bölge olduğu için özellikle bu bölgede öngörülen kararlar detaylı incelenmiştir.

Çevre Düzeni Planının açıklama raporunda (URL-4, 2017), planın hedef yılı olan 2025 yılı için Alanya'nın turizm potansiyeline, dolayısıyla hizmet sektöründeki gelişmeler nedeniyle iş olanaklarının artmasına ve göç almasına bağlı olarak nüfusunun çok fazla artacağı düşünülerek projeksiyon nüfusunun hesaplandığı belirtilmiştir. Bunun mekânsal yansımaları olarak Çevre Düzeni Planında kıyı boyunca kentsel gelişme alanı ve turizm tesis alanları (buna bağlı altyapı yatırımları) öngörülmüş, hemen hemen kentsel yerleşik alan büyüklüğünde (yerleşik alanın yaklaşık \%76'sı kadar) kentsel gelişme alanı ayrılmış ve yayılmaya odaklı bir kent formu benimsenmiştir (Şekil 4). Kentsel yayılmanın tarım ve orman arazilerini tehdit ettiği ya da yok ettiği aşikardır. Ayrıca gelecekte yine turizm sektörü odaklı bir gelişme öngören planın olası iklim değişikliği tehlikelerine karşı alternatifler barındırmadığı çıkarımı yapılabilir. 


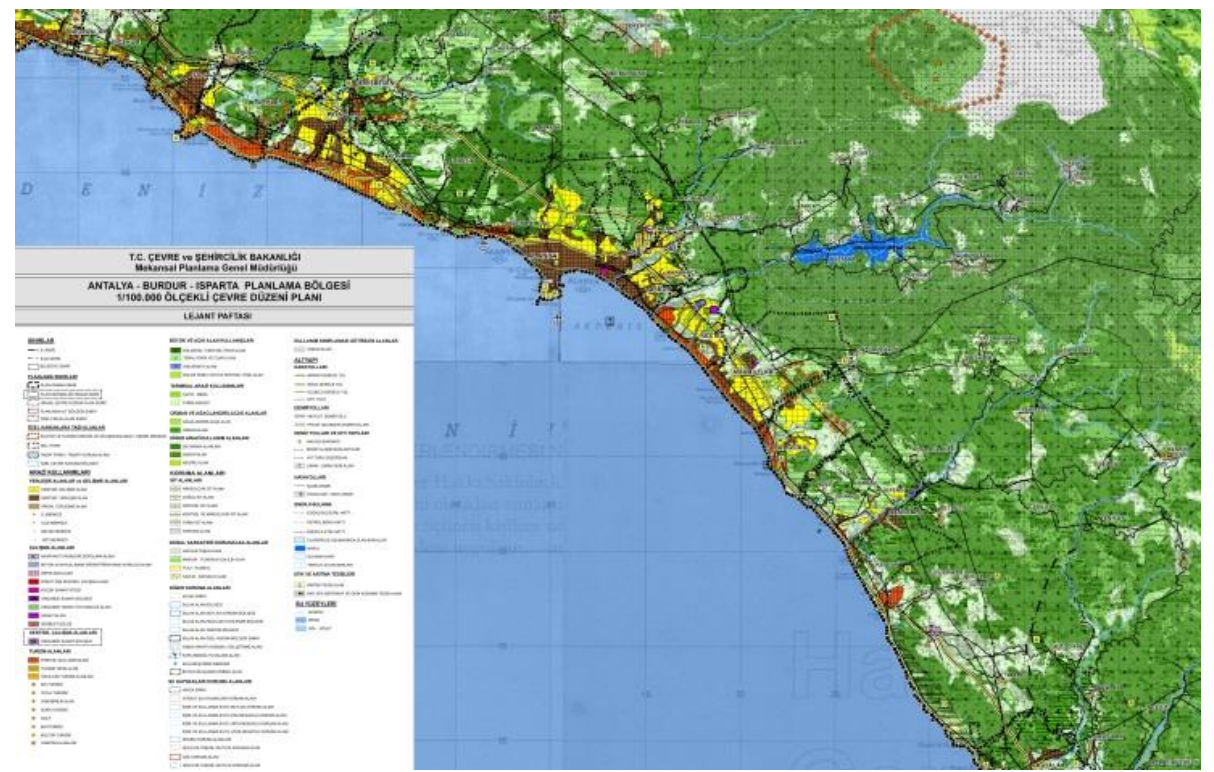

Şekil 4. Çevre düzeni planı

Taşkın riskine karşı en kırılgan yapıda olan ve öncelikli müdahale gerektiren düşük rakımlı kıyı bölgesi için öngörülen sektörel ve mekansal gelişim kararlarında; kentsel yerleşik alan, kentsel gelişme alanı, tercihli kullanım alanı, sanayi alanı, turizm tesis alanı, üniversite ve tarım alanları kullanımları bulunmaktadır (Şekil 5).

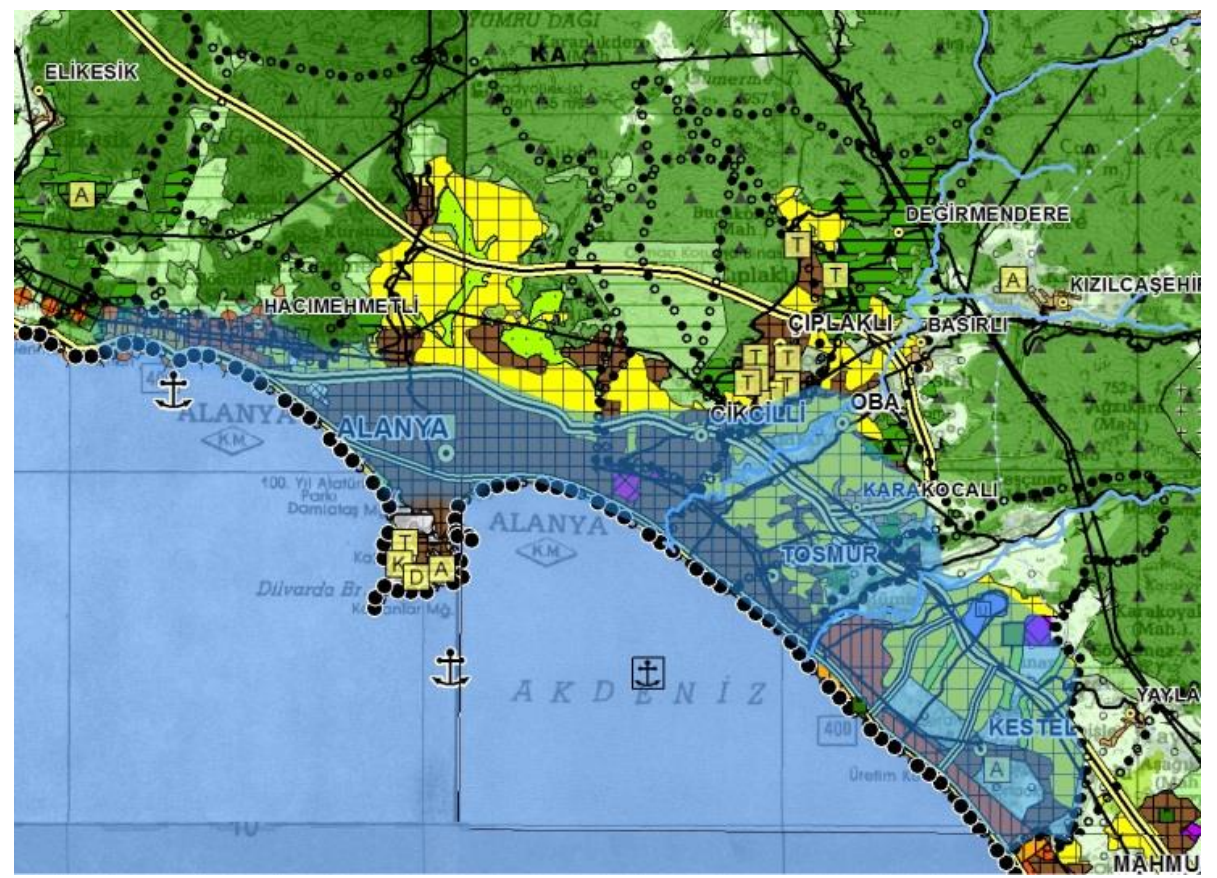

Şekil 5. Çevre düzeni planında düşük rakımlı kıyı bölgesi için öngörülen sektörel ve mekansal gelişim kararları

Görüldüğü gibi düşük rakımlı kıyı bölgesi taşkın açısından riskli alan kabul edilmemiş, bu doğrultuda kentsel gelişme alanları ve tercihli kullanım alanları (turizm tesis alanları veya kentsel yerleşme alanı olarak kullanılacak alanlar) öngörülerek ya da herhangi bir gelişim sınırlandırması getirilmeyerek kırılganlığı göz ardı edil- miştir. Ayrıca plan açıklama raporunda, nüfus projeksiyon değerleri doğrultusunda Alanya ilçesi için öngörülen nüfus gelişimleri ve yoğunluklarının yerleşimlerin özellikleri değerlendirilerek kabulle yapıldığı ifade edilmiştir. Buna ek olarak kentsel gelişme alanlarındaki bölgesel yoğunluk dağılımının projeksiyon nüfusu göz 
önüne alınarak, ilgili idaresince alt ölçekli planlarda belirleneceği hükme bağlanmıştır. Buna göre, yüksek yoğunluklu ve kentsel ISı adası etkisinin fazla olduğu kentsel yerleşik alanlara yakın bölgelerde ve/veya aynı nitelikte önerilen kentsel gelişme alanları için de benzer yoğunluk değerlerinin kabul edildiği / edileceği düşünülebilir. Yapılı çevrenin yapısı ve kompozisyonunun kara yüzey sıcaklık desenleri üzerinde önemli etkiye sahip olduğu, bu bağlamda arsa ve bina inşaat oranlarının, binalar arası mesafenin, arazi kullanımının, bitki örtüsünün vb. buna katkısı olduğu araştırmacılar tarafından ortaya konulmuştur (Eliasson, 1996; Bottyan ve Unger, 2003; Dousset ve Gourmelon, 2003; Weng ve ark., 2004). Araştırmalarda, konut yoğunluğunun ve geçirimsiz yüzeyin fazla olduğu alanların daha sıcak olduğu görülmüştür. Çevre Düzeni Plan kararlarına göre Alanya'nın iklim değişikliğine bağlı aşırı sıcak hava dalgası riskine ek olarak öngörülen nitelikte bir yapılı çevreyle kara yüzey sıcaklıklarının daha da artabileceği söylenebilir.

Öte yandan, Çevre Düzeni Planının amaç, ilke, tanım ve plan hükümlerinde, iklim değişikliğine ilişkin herhangi bir ifade ve hükmün bulunmadığı; Planlama Bölgesi'nin koruma hedef ve stratejileri arasında doğal, tarihsel ve kültürel değerleri, verimli tarım topraklarını, orman alanlarını ve hassas alanları koruma hedeflerinin belirlenmekle birlikte, bu hedef ve stratejilerin iklim değişikliğine adaptasyonla ilişkisinin kurulmadığı; kentsel yerleşmelerde afet riski de dikkate alınarak nüfus gelişiminin sürekli denetlenmesinin esas olduğu ilkesinin belirlenmiş olduğu, ancak afet riski kapsamında iklim değişikliği konusunun değerlendirilmediği görülmektedir.

Kısaca, Çevre Düzeni Planı iklim değişikliği gerçeğini dikkate alarak mekânsal uyum stratejileri ve kararları geliştirmemiştir. Dolayısıyla plan, iklim değişikliğine karşı Alanya'nın kırılganlığını veya savunmasızlığını azaltmayı, esneyebilirliğini / direncini artırmayı desteklememektedir. Bu nedenle bu planla Alanya'nın iklim değişikliği tehdit ve etkilerine uyum sağlama yeteneği / esneyebilme gücü oldukça düşüktür.

\section{ALANYA'NIN UYUM KAPASITESININ GÜÇLENDİ- RILMESINE YÖNELIK MEKANSAL STRATEJILER}

İklim değişikliği tehditlerine, deniz seviyesinin yükselmesi ve aşırı sıcak hava dalgalarına, maruz kalması ve bu tehditlerin etkilerine uyum sağlama ve / veya iyileşme direncinin Çevre Düzeni plan kararları yani morfolojik yapısı gereği zayıf olması nedeniyle Alanya kırılgan bir yapıya sahiptir.

Bir yerleşimin uyum sağlayabilme yeteneği, esneyebilirlik tartışmalarının merkezini oluşturmakta ve planlama kararları açısından önem arz etmektedir. Bir yerleşimin esneyebilirliğini belirleyen unsurlar, iklim değişikliği etkilerine nasıl tepki verdiği ile ilişkilidir. Bu kapsamda uyum kapasitesinin güçlendirilmesi, iklim değişikliğinin üstesinden gelebilmek için uygulanabilir bir yolun tanımlanması ve kaynakların niteliği ve nasıl kullanılması gerektiği konusunda çıkarımlar yapılması anlamına gelmektedir (Folke ve Carpenter, 2000). İklim değişikliğinden kaynaklı riskler, kentleşme ve kırılganlık arasındaki etkileşim dikkate alındığında, arazi kullanım politikaları ve planlaması uyum kapasitesinin güçlendirilmesinde önemli bir araçtır. Kentsel arazi kullanım planlaması yoluyla Alanya'nın mekânsal kııılganlıklarını azaltacak veya uyum kapasitesini güçlendirecek stratejiler neler olabilir? Alanya için hangi müdahale ya da müdahaleler öncelikle hayati önem taşımaktadır? soruları bu çerçevede önem kazanmaktadır.

Uyarlama yolları ya da seçenekleri; potansiyel etki ve uyum kapasitesi karşılaştırması yapılarak, dolayısıyla tipolojiler belirlenerek tanımlanabilir. Bu çerçevede iki temel uyarlama yolu belirlenebilir:

1. Yol: Yüksek düzey potansiyel etkiye ve düşük uyum kapasitesine sahip alanları içerir. Alanya'nın düşük rakımlı kıyı bölgesi, gelecekte taşkın riskine maruz kalma olasılığı ve mevcut arazi kullanımı ve Çevre Düzeni Planı kararları gereği uyum kapasitesinin düşük olmasına bağlı olarak büyük can kaybı ve ekonomik zararların yaşanabilme olasılığı nedeniyle en hassas alandır. Adaptasyon planlamasında da temel müdahale alanı ya da birinci öncelikli alan olmalıdır. Bu alanda dayanıklıığı / uyumu artırmak için geliştirilebilecek mekânsal stratejiler ve eylemler şöyle sıralanabilir:

- Kıyı ekosisteminin korunması için önlemler geliştirilmesi (ör. taşkın risk yönetimi planının hazırlanması),

- Taşkın ve tuzlu su sızdırmasına adapte etmek için altyapının iyileştirilmesi (drenaj kapasitesinin artırılması), esnekliğinin artırılması,

- Taşkın riskine karşı belli alanların koruma alanı olarak belirlenmesi. Olası tehlike sonrası tahliye için alanların ayırılması,

- Bu alanda mekânsal gelişmenin olmaması ya da sınırlandırılması,

- Liman altyapısının korunması için önlemler alınması,

- Bina yönetmeliklerinin güvenlik tedbirlerini, yenilenebilir inşaat uygulamalarını içerecek biçimde yeniden düzenlenmesi (ör. su basman seviyelerinin yükseltilmesi, güç kaynağı kutularının daha yukarı yerleştirilmesi) vb.

Kentsel Isı adası etkisinin fazla olduğu ve / veya olacağı alanlar ikinci öncelikli alanlar olarak değerlendirilebilir. Bu alanlarda sıcaklık kaynaklı sağlık riskinin artması, buna bağlı konforun azalması, soğutmaya bağlı 
enerji tüketiminin ve maliyetin artması, yüksek nüfus yoğunluğuyla birlikte kentsel altyapıdaki stres düzeyinin artması vb. potansiyel etkiler görülebilir. Mevcut durumda ve Çevre Düzeni Planında açık/yeşil alanların veya geçirimli yüzeylerin yüksek yoğunluğa oranla oldukça az olması düşük adaptif kapasiteye yol açmaktadır. Bu alanlarda dayanıklıığı / uyumu artırmak için geliştirilebilecek mekânsal stratejiler ve eylemler şöyle sıralanabilir:

- Bir sistem dahilinde kentsel yeşillendirmenin artırılması (konut çatısı, bahçesi, refüj, çocuk bahçesi, park alanları dahil) ve erişilebilir olması. Uygun alanların "ağaçlandırılacak alan" olarak belirlenmesi,

- Arazi kullanım planlaması ile yeşil altyapı planlamasının bütünleştirilmesi,

- Soğutma amaçlı artan elektrik kullanımının yenilenebilir enerji kaynaklarından (ör. güneş enerjisi) karşılanması,

- Mevcut bina stoğunun uyum kapasitesinin / termal performansının artırıması (bina cephesi, çatısı, bina içi için uyarlanabilir seçeneklerin geliştirilmesi), bunun için finansman sağlanması,

- Yeni yapılacak binaların yönlenme, tasarım ve inşasında uyum kapasitesini artıracak çözümlerin üretilmesi, ilgili bina yönetmeliklerinin yeniden düzenlenmesi / iyileştirilmesi,

- Kentsel gelişme alanlarında yoğunlukların sınırlandırılması vb.

2. Yol: Orta düzey potansiyel etkiye ve düşük uyum kapasitesine sahip alanları içerir. Bahsi geçen yüksek potansiyel etkiye sahip alanlar dışında Alanya'nın geriye kalan alanları, özellikle ormanlar, tarım arazileri ve su kaynakları bu kapsamda değerlendirilebilir. Yüksek potansiyel etkiye sahip alanlar dışında kalan alanlar, özellikle sıcaklık artış riskine maruz kalma olasılıkları (tarımsal verimliliğin ve su kaynaklarının azalması, turizm talebinin düşmesi vb. etkiler) nedeniyle öncelikli müdahale alanlarından sonra ele alınabilecek alanlar olabilir. Mevcut arazi kullanımda ve Çevre Düzeni Planında iklim değişikliği riskleri dikkate alınmadığı için bu alanlar düşük uyum kapasitesine sahip alanlar olarak ele alınabilir. $\mathrm{CO}_{2}$ tutma kapasitesine sahip yutak alanlar olarak adlandırılan ormanlar, tarım arazileri ve su kaynakları ise iklim değişikliği potansiyel etkilerine dolaylı yoldan maruz kaldıkları için orta düzey potansiyel etkiye maruz kalabilecek alanlar kapsamında değerlendirilebilir. Kentsel gelişme taleplerine bağı baskılarla azalma veya yok olma tehlikesi altında oldukları için de düşük uyum kapasitesi ile nitelendirilebilirler. Bu alanlarda dayanıklılığı / uyumu artırmak için geliştirilebilecek mekânsal stratejiler ve eylemler şöyle sıralanabilir:

- Ormanların ve tarım arazilerinin korunması, yapılaşmaya açılmaması,
- Su kaynaklarının taşıma kapasitesine göre nüfus projeksiyonlarının yapılması,

- Su kaynaklarının korunması ve yönetilmesi,

- Enerji verimliliğini sağlayacak sürdürülebilir kentsel formun (yayılma yerine kompakt form) tercih edilmesi,

- Kentsel dönüşümün bir fırsat olarak değerlendirilerek mekânsal iyileştirmelerin sağlanması, konut kalitesinin artırılması,

- Alternatif / yeni ekonomik faaliyetlerin geliştirilmesi vb.

Tüm uyarlama yolları için, "erişilebilir, verimli, güvenli ve konforlu mekânsal yapılanmanın sağlanması", "etkin bir arazi kullanım planlaması ve altyapı planlamasının yapılması", "iklim değişikliğini dikkate alan ve yeterli düzeyde uygulanan düzenleyici sistemlerin oluşturulması", "iklim değişikliği etkilerine karşı esnek bir ulaşım ağının oluşturulması", "konut stoğunun afet direncinin artırılması" vb. genel stratejiler olarak belirlenebilir.

\section{SONUÇ}

Aşırı hava olaylarıyla karakterize edilen iklim değişikliği, uzun vadede ülkemiz yerleşimlerini çeşitli düzeylerde etkileyecektir. Şimdiden adaptasyon intiyaçları ve seçenekleri üzerine plan ve politikalar geliştirmek, gerekli yatırımları ve düzenlemeleri yapmak, yerleşimlerin olası felaketlerden daha az etkilenmelerini sağlayacaktır. Bu kapsamda kentsel arazi kullanım politika ve planları, yerleşimlerin esneyebilirlik ve dayanıklıığını geliştirerek iklim değişikliğine uyum sağlamayı amaçlamalı, yerleşimleri geleceğe ve gelecekte ortaya çıkabilecek koşullara ne ölçüde hazırlayabildikleri başarılarının ölçütü olarak kabul edilmelidir.

Bir yerleşimin esnekliği için temel oluşturan uyum kapasitesi; altyapı ve hizmetlerin ne kadar sağlandığına ve kalitesine, yatırımların ve arazi kullanım yönetiminin kapasitesine ve binaların ve altyapının sağlık ve güvenlik standartlarını karşılama derecesine bağlıdır. Öte yandan uyum kapasitesi, merkezi ve yerel yönetimin iklim değişikliğine uyumu kalkınma planlarına, politikalarına ve altyapı yatırımlarına dahil edip etmemeleriyle de yakından ilişkilidir (Revi ve ark., 2014). Bu ilişki, mekânsal, sosyal, yasal, kurumsal, finansal, yönetişim, davranışsal vb. açılardan çok boyutlu önlemleri gerekli kılar.

\section{KAYNAKLAR}

Balica, S. F., Wright, N. G., Van Der Meulen, F. (2012). A flood vulnerability index for coastal cities and its use in assessing climate change impacts. Natural Hazards 64(1): 73-105.

Bottyan, Z., Unger, J. (1996). A multiple linear statistical model for estimating the mean maximum urban heat island. Theoretical and Applied Climatology 75: 233-243.

Cutter, S. L., Boruff, B. J., Shirley, W. L. (2003). Social vul- 
nerability to environmental hazards. Social Science Quarterly 84(2): 242-261.

Dousset, B., Gourmelon, F. (2003). Satellite multi-sensor data analysis of urban surface temperatures and landcover. ISPRS Journal of Photogrammetry and Remote Sensing 58: 43-54.

Eliasson, I. (1996). Urban nocturnal temperatures, street geometry and land use. Atmospheric Environment 30: 379-392.

Eliasson, I., Thorsson, S., Eraydin, A., Alcoforado, M. J. (2010). Urban Tourism and Climate Change. FORMAS (The Swedish Research Council for Environment, Agricultural Sciences and Spatial Planning), Urban-Net.

Eraydın, A., Türel, A., Altay, D., Gürçay, M., Özonat, Ç., Uluışık, B. (2011). Yeni Koşullara Uyum Sağlayabilen ve Kendini Yenileyebilen Kentler Için Sürdürülebilir Arazi Kullanım Politikaları. Proje raporu, TÜBITAK, Proje No: $108 \mathrm{~K} 613$.

Folke, C., Carpenter, S. (2000). Resilience and Sustainable Development: Building Adaptive Capacity in a World of Transformations. Stockholm: Edita Norstedts Tryckeri AB.

Hawkins, HT.W., Brazel, A.J., Stefanov, W.L., Bigler, W. , Saffell, E.M. (2004). The role of rural variability in urban heat island determination for Phoenix. Arizona J. Appl. Meteorol 43: 476-486.

Öztürk, M.Z. (2011). Gel-git ölçüm istasyonu verilerine göre doğu Akdeniz'de deniz seviyesi değişimleri ve bu değişimlerin iklim elemanları ile ilişkileri: 1972-2009. Uluslararası İnsan Bilimleri Dergisi 8 (2): 628-642.

Revi, A., Satterthwaite, D. E., Aragon-Durand, F., CorfeeMorlot, J., Kiunsi, R. B. R., Pelling, M., Robert, D. C., Solecki, W. (2014). Urban areas. In: Climate Change: Impacts, Adaptation, and Vulnerability. IPCC, Cambridge University Press, Cambridge, United Kingdom and New York, NY, USA, 535-612.
Sensoy, S., Demircan, M., Alan, İ. (2007). 1971 - 2004 Yılları arası Türkiye iklim indisleri trendleri. Turkish State Meteorological Service, Ankara.

Türkeş, M. (2001). Hava, iklim, şiddetli hava olayları ve küresel isınma. The Seminars of 2000 of Turkish State Meteorological Service, Technical Presentations, Series of Seminars:1, Ankara,187-205.

URL-1 (2017). Alanya İlçesi Belediyeleri Coğrafi Bilgileri, http://www.yerelnet.org.tr/ilceler/ilce_belediye_koordinat.p hp?ilceid=198281, (Erişim Tarihi: 25.07.2017).

URL-2 (2007). Antalya II Çevre Durum Raporu 2007, http://antalyaobm.ogm.gov.tr/Documents/\%C5\%9Eube\%2 0Cetvelleri/kadastro\%20m\%C3\%BClkiyet\%20\%C5\%9Fub e\%20m\%C3\%BCd\%C3\%BCrl\%C3\%BC\%C4\%9F\%C3\%B C/PDF_TUTANAKLAR_11_08_2011/muratpa\%C5\%9Fa tutanaklar_pdf/antalyaicd2007.pdf, (Erişim Tarihi: 22.07.2017).

URL-3 (2015). Antalya İli 2015 Yılı Çevre Durum Raporu, http://www.csb.gov.tr/db/ced/editordosya/Antalya\%20cevr e\%20durum\%20raporu\%202015.pdf, (Erişim Tarihi: 22.07.2017).

URL-4 (2017). Antalya Burdur Isparta Planlama Bölgesi 1/100.000 ölçekli Çevre Düzeni Planı Açıklama Raporu, http://www.csb.gov.tr/db/mpgm/editordosya/file/AntalyaBurdur Isparta\%20Planlama\%20Bolgesi/PLAN_ACIKLAMA_RAPORU 15042014.pdf, (Erişim Tarihi: 19.07.2017).

Watts, M. J., Bohle, H. G. (1993). The space of vulnerability: the causal structure of hunger and famine. Progress in Human Geography 17: 43-67.

Weng, Q. H. L., Lu, D. S., Schubring, J. (2004). Estimation of land surface temperature - vegetation abundance relationship for urban heat island studies. Remote Sensing of Environment 89: 467-483. 